\title{
MAF Family Protein
}

National Cancer Institute

\section{Source}

National Cancer Institute. MAF Family Protein. NCI Thesaurus. Code C18546.

Maf family proteins possess a highly conserved basic leucine zipper (bZip) domain and are subdivided into large and small Maf proteins. The Maf family proteins appear to regulate cell differentiation processes and also cellular functions as partner molecules of CNC family proteins. (from Cytogenet Cell Genet 1998;82:88-90 and CGAP) 